\section{Industrial action}

SIR,-The profession has at last reacted in unity to the scandalous fall in our living standards over the past three years.

Now that we are at last united, general practitioners, consultants, and junior staff, let us stand and fight this Government for a fair remuneration, because, make no bones about it, the only way to see our living standards restored is to adopt the tactics of militant trade unionism.

It will mean unprofessional tactics and suffering for the profession and the general public, but this time we must support militant action or for ever be branded as a "soft touch" by any government of either political inclination.

Solihull, Warks

JOHN TAVERNER

SIR,-Working as I do outside the National Health Service, and perhaps seeing more clearly what is happening, I would like to urge the consultants to think again before taking part in the one-day strike supported with such enthusiasm at the recent BMA meeting in Glasgow. It cannot be emphasised too strongly that such action is not only futile as an attempt to achieve political or financial objectives, but it goes so directly against the inclinations and training of doctors in patient care that it will never be wholeheartedly supported, it is degrading to an honourable profession, and it is bound to alienate the sympathy of the public and patients for whatever cause the consultants wish to espouse.

When one sees the strike tactics adopted by the various unions in Britain it is tempting to think that objectives can be achieved only by adopting similar attitudes. What one must realise, however, is that it is just those tactics that have brought so many public industries and institutions to the abysmal state that they now occupy in the public mind and in the minds of our competitors overseas. The adoption of such behaviour by the medical profession can only lead to a similar degrading of medicine in this country, and it is a measure of how far things have already gone that such courses of action are even suggested.

If the profession feels that the conditions in the NHS are now so far removed from what was promised or contemplated in 1948, when they agreed to join a State service, the only honest and honourable thing that can be done is to resign. At first sight this would appear to be economically impossible, but nothing is worth while without some sacrifice. In fact, with planning and leadership this could be minimised. What is required is for the BMA or some organisation commanding the respect of the profession to set up a bureau to supply medical services to the NHS. Substantial funds might need to be collected from the profession to set things in motion, but this is part of the sacrifice. Appropriate charges would need to be drawn up for supplying surgeons to operate and provide postoperative care and for physicians to look after patients in wards and run outpatient clinics. It may be necessary at first to set the charges at levels encountered in North America, but as funds accumulate reductions could be made to bring charges and remuneration more in line with that in the Common Market and the rest of western Europe. Of course in the early days of such a scheme it would be necessary to share earnings more or less equitably between those en- gaged in medical work and those still waiting for service contracts to be drawn up to defeat attempts to force consultants into submission by a reduction in total medical care. This, however, would not last very long, such is the demand for medical services in a sophisticated society.

Once an effective plan for medical care and remuneration of consultants has been drawn up, then the 11000 who are said to be represented by the strike resolution at the BMA conference could hand in their resignations, giving three months' notice. I don't really need to point out that if the senior members of the profession showed a clear determination to withdraw from service in the NHS, completely new negotiating terms would be drawn up by the Government, which would not only correct the anomalies and inadequacies in medical remuneration but would enable the profession to regain its control and influence over the totality of medical care in this country.

Owing to lack of leadership and concerted action the doctors have now handed over al meaningful influence in the organisation of medical affairs, to the great detriment of patients. It was fashionable a few years ago to hear such glib phrases as "medicine is too serious a matter to be left in the hands of doctors." One would like to know who else apart from the medical and nursing professions has the knowledge of what is needed in medical care and who else has the direct responsibility for the patients' interests by the very nature of his or her training ? Not the unions, who use patients as pawns in the game of restrictive practices and overmanning. Not the administrators, who clog all the machinery necessary to deliver twentieth-century patien care to the bedside and clinic. Not the politicians, who would willingly sacrifice patients on the altar of political dogma.

Any worth while health service needs the direction and leadership of the senior members of the medical and nursing professions, who have the ability and experience to translate finance into medical care, at the same time creating a pleasant working environment with the necessary discipline to ensure that such care is responsibly and effectively delivered at all levels.

Today medicine in this country is a depressed industry and the signs at the moment are that it is moving towards complete inertia with occasional outburst of hysteria. It is not too late to apply the remedy and perhaps set an example to other depressed industries and organisations in this country.

Ashtead, Surrey

DeNIS BuRLEY

SIR,-Once more the question has arisen about "industrial" action by doctors, entered into for the purpose of getting more money. Anything which hurts NHS patients is immoral and ineffective. Why has nobody suggested the ethical and effective alternative-to refuse to see patients privately? Influential persons, including Cabinet ministers, would be invited to sit in surgeries and outpatient departments. In this way doctors would not only apply pressure in the right quarter but would gain public support rather than censure.

Churchill Hospital,

A I SPRIGgs
SIR,-As a retired general practitioner who qualified in 1922 I wish to record my objection to any form of strike in our profession. All strikes are forms of blackmail. I share the oftrepeated views of my friend, Dr Ian MacLeod of the USA and late of Strathpeffer, who blames the royal colleges for agreeing to joining the NHS in 1948 and thereby influencing the decisions of GPs to make a similar error

I should be more in favour of resignation by all doctors, with future and permanent independence from any government-and above all from trade unionism. Any student of political history must have known that any form of nationalisation has failed.

R C McIntosh

Sturry,

Canterbury, Kent

SIR,-If as a result of the cynical disregard of the welfare and the calculated lowering of the status of the profession by successive Ministers of Health and their Cabinet colleagues, the frustration and disillusionment felt by doctors working in the NHS has so lowered their morale that the Service is facing disintegration, then pre-emptive action becomes urgent. Experience has shown that it is both pointless and futile to indulge in work-to-contract, oneday strikes, and refusal to sign certificates. A gnat makes little impression on an elephant. The miners told the Government, "Without us you will have no coal"; that is industrial muscle. Parliament has placed upon the Government a statutory duty to provide a National Health Service. Doctors should tell the Government, "Without us you will have no National Health Service"; that is industrial muscle.

We should have the self-respect and the guts to resign from the National Health Service.

Bournemouth

Alan Ogden

SIR,-The medical profession has always been regarded as a responsible profession and one might have expected it to act responsibly at a time of acute economic crisis and galloping inflation (in which every section of the community shares)

We are appalled that at the Annual Representative Meeting of the BMA in Glasgow an inflationary claim for increased salary should have been made, with threats of industrial action and disruption of the National Health Service. Inflationary claims at this time can only aggravate the overall economic situation and are inevitably at the expense of such groups as pensioners, of whose problems we are well aware.

The NHS is sick enough without our help in finishing it off and if we persist in pressing such a claim at this time our status as a profession, already regrettably low, will be irretrievably lost.

IAN W FINGLAND

Greenlaw, Berwickshire

MARGARET J FINGLAND

\section{Overseas doctors' difficulties}

SIR,-As editor-in-charge of the $O D A$ News I was more than a little interested in Professor George Dick's report of a symposium for overseas doctors (16 July, p 206). I have sent him some recent copies of the $O D A$ News, which I 
trust will be informative and useful for the next symposium.

It is reported that none of the participants were members of the Overseas Doctors Association. I wonder how many, if any, of them were advised to acquaint themselves with the aims of objectives of the ODA, and indeed why the ODA was formed at all. As you know, between the BMA and Merrison the overseas doctors felt miserably let down. The ODA is an outcome of this failure. However, the aim of the ODA is to work itself "out of office" when the BMA, the DHSS, and other bodies recognise the importance and the need of these overseas doctors as a way of British life.

I am happy to note that you have reported the recommendations of the Community Relations Commission. The ODA has pointed out over and over again the lack of information from the Postgraduate Medical Federation, the unhelpfulness of the GMC, lack of constructive information to and from the various high commissions, poor screening and political shadow-boxing in the home countries of many of the immigrant doctors, the undue prominence and injustice of the TRAB test in its present form, etc. The ODA has advocated the subject of physical and emotional acclimatisation of overseas doctors from the third world and abolition of temporary registration (after passing the TRAB test), a blatant form of discrimination in the present context.

Professor Dick has underlined all that the ODA has said about lack of sympathy, coordination, and inadequate counselling of immigrant doctors in a strange host community and already crucified by adverse propaganda. $\mathrm{He}$ has most admirably put together his analyses of the great difficulties the overseas doctors face in attachments, counselling, and job and career prospectssensitive matters discussed by him in a sensitive manner. He goes on to say that if the existing machinery could not operate satisfactorily, then the ODA might have to become more active. I would like you to know that in about 18 months of its existence the ODA has 24 branches and divisions scattered over the country, including Northern Ireland. All of these are more active, area for area, than the BMA (I am a member of the executive committee of my division, and a representative to the ARM).

It was mentioned that the ODA had been invited to the symposium but had not responded. This is a matter of great surprise to the members of the Executive Committee of the ODA, and no doubt the general secretary or the chairman of the association will clarify the matter.

Loughton, Essex

S C BHATTACHARYA

\section{Common waiting lists}

SIR,-In the report by the Health Services Board on common waiting lists for NHS hospitals $^{1}$ at the end of paragraph 9.4 there appears this sentence: "Occasionally, because of under-use of pay beds, private patients are able now to gain early admission in circumstances when it would not be granted to an NHS patient; this should no longer happen if common waiting lists are introduced."

This sentence seems to me to contain the nub of the argument. A private bed may be available, the patient is willing and ready to go into it, but is to be held back deliberately because NHS beds are not available to NHS patients of equal medical priority.

It is clear that there are two queues-one for private beds and one for NHS beds-just as there may be separate queues in a street for buses and taxis. Common waiting list for two separate queues are a farce written to justify the oft-repeated gibe against private patients of "queue-jumping."

Private patients requiring hospital care are fully entitled to an NHS bed and could easily make that queue longer. If they choose to pay, and pay heavily, for the privilege of a private bed how can this Government justify deliberately keeping them out of hospital by the tawdry device of "common waiting lists ?" Is it equitable for the taxi to wait until the bus is loaded and then ensure that one doesn't arrive at the destination a second before the other?

Ipswich

P A T Woon

Common Waiting Lists for NHS and Private Patients in NHS Hospitals: Report of the Health Services Board made under section 6, Health Services
1976. Cmnd 6828. London, HMSO, 1977.

\section{Proclaim it upon the housetops}

SIR,-Once again one notices the deliberate omission of parts of the whole truth by the BBC, thus deliberately building public opinion against the doctors' case for a reasonable restoration of their living standard, and our case is lost. We will even be maligned. There is a clear case for presentation to Britain of clear truth, well and impartially spoken, and repeated over weeks on ITV.

I suggest a condensation from Dr KeableElliott's letter to general practitioners dated 12 July 1977 on these lines, to the point, and without woolliness: "The living standards of doctors will have fallen by about $23.6 \%$ between April 1975 and April 1977. The fall in living standards over the same period of the average wage and salary earner is expected to be $6 \%$. If nothing can be done until April 1978 the doctors' standard of living will have fallen by over $60 \%$."

Please, British Medical Association, get on your hind legs and fight-not with dull and harmful strikes but with truth and high skill.

Blairgowrie, Perthshire

M M SHEPHERD

\section{Doctors and administrators}

SIR,-I was saddened to read $\mathrm{Mr} \mathrm{R} \mathrm{L} \mathrm{L}$ Simmons's letter (9 July, p 129) entitled "administrative obstructionism."

I have no wish to debate the individual issue as I have insufficient information to do so. What saddened me was the readiness to generalise from an individual case. We all know of individual cases of irrational obstruction by every profession in the Health Service. But most of us endeavour to maintain a sense of proportion and not leap from the particular to the general in a single Olympic feat of intellectual genius. Since when has the medical profession, for which I have immeasurable admiration, claimed "tangible proof" from a sample of one?

The artificial dispute between a minority of doctors and a minority of administrators, both of whom are subject to any deficiencies in the organisation of the Service, has continued long enough. It is high time we discarded such childishness, fit only for television serials, and thrashed out our common problems in a friendly and constructive manner. Not until we do so will the patient get the best service that we can give.

Edinburgh

Peter A Hill

\section{Points from Letters}

\section{Postponing premature labour}

Dr IAN KenNedy (Bamalete Lutheran Hospital, Ramotswa Village, Botswana) writes: With reference to your leading article (30 April, p 1118).... Lipshitz et al ${ }^{1}$ compared the $\beta_{2}$-mimetics fenoterol, hexoprenaline, ritodrine, and salbutamol and their effect on uterine activity and found hexoprenaline to be the most satisfactory.

'Lipshitz, J, Baillie, P, and Davey, D A, South African
Medical fournal, 1976, 49, 1969.

\section{Television epilepsy}

Dr D G French (Kidsgrove, Staffs) writes: . . . I have found, unexpectedly, that viewing television through an aperture about $2 \mathrm{~mm}$ in diameter eliminates flicker. Perhaps it would be worth while to make use of this observation in a clinic with access to suitable cases to see if it prevented fits in susceptible epileptic subjects.

\section{The coughing that gets them down}

Dr M SUPER (Windhoek, $S$ W Africa) writes: ... Your leading article (28 May, $p$ 1374) . . makes no reference to cystic fibrosis as a cause of chronic cough. Surely a mention separate from chronic bronchitis was deserved, the treatment of the cough being physiotherapy mainly and absolute avoidance of cough suppressants. Enough people with cystic fibrosis reach adulthood to justify its insertion in the differential diagnosis of cough at any age.

\section{Telling the patient}

Dr D MuRPhy (Radcliffe Infirmary, Oxford) writes: In your leading article on pathological fractures (2 July, p 4), you state that "most sufferers from malignant disease expect to share the truth of their plight." I would dispute this statement. What is your evidence?

\section{Malaria in returning travellers}

Dr P Dransfield (Huddersfield) writes: ... As pointed out by $\operatorname{Dr} R$ G Thompson and others (4 June, $p$ 1468) there is the possibility of malaria being imported by visitors to and from the Indian subcontinent. However, the visit is not always a very recent one. Two cases of malaria have been found in recent weeks in practice here. One man had returned in May 1976 from a visit to India and the other had returned to this country in January 1977 after visiting Pakistan. . . . In one the interval before symptoms and signs developed was over a year and in the other six months. 